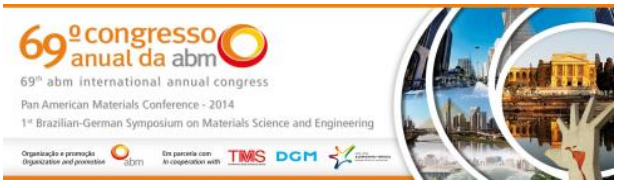

Tema: Materiais com efeito de memória de forma

\title{
OTIMIZAÇÃO DAS CONDIÇÕES DE TRATAMENTO TÉRMICO DE SOLUBILIZAÇÃO E ENVELHECIMENTO EM LIGA FORJADA DE NiTi RICA EM Ni PARA APLICAÇÕES SUPERELÁSTICAS*
}

\section{Resumo}

Edir Neves Teixeira' Andersan dos Santos Paula ${ }^{2}$ Shimeni Baptista Ribeiro ${ }^{3}$ Alessandra Motta Streva 4

O presente trabalho teve como objetivo o estudo para otimização de distintas condições de tratamentos térmicos de solubilização e envelhecimento em liga forjada de NiTi rica em Ni visando características e propriedades adequadas para aplicações superelásticas. As características microestruturais e composicionais foram avaliadas por Difração de Raio-X (DRX), por Microscopia Eletrônica de Varredura (MEV) associada à Difração de Elétrons Retroespalhados (EBSD) e ao Espectrômetro de Energia Dispersiva de Raio-X (EDX), e correlacionadas com as medidas de dureza Vickers. Baseados em resultados da literatura, apresentou características mais promissoras para tratamentos de solubilização a $950^{\circ} \mathrm{C}$ por 120 minutos conjugado com envelhecimento a $350^{\circ} \mathrm{C}$ por 30 minutos, ambos com resfriamento em água.

Palavras-chave: Liga de $\mathrm{NiTi}$ rica em Ni; Solubilização; Envelhecimento; Superelasticidade.

\section{OPTIMIZATION OF SOLUBILIZATION AND AGING HEAT TREATMENT CONDITIONS Ni RICH Ni-Ti ALLOY FORGED WIRE FOR SUPERELASTIC APPLICATIONS}

\section{Abstract}

The present work aimed to study the optimization of different conditions of solubilization and aging treatments applied to forged Ni-rich NiTi alloy aiming suitable characteristics and properties for superelastic applications. The microstructure and composition characteristics were evaluated by X-Ray Diffraction (XRD), by Scanning Electronic Microscopy (SEM) associated with Electron Backscattered Diffraction (EBSD) and Energy Dispersive X-Ray Spectrometer (EDS), and correlated with Vickers hardness measurements. Based on literature results, shown more promise characteristics by solubilization heat treatment at $950^{\circ} \mathrm{C}$ by 120 minutes conjugated with aging heat treatment at $350^{\circ} \mathrm{C}$ by 30 minutes, both cooled in water.

Keywords: Ni-rich NiTi alloy; Solubilization; Aging; Superelasticity.

\footnotetext{
Engo Metalúrgico, MSc, Professor em Enga Mecânica, UniFOA, Volta Redonda, RJ, Brasil. Enga Metalúrgica, DSc, Prof. Adjunta, EEIMVR, VMT e PPGEM, UFF, Volta Redonda, RJ, Brasil. Eng ${ }^{a}$ Metalúrgica, Doutoranda em Eng ${ }^{a}$. Metalúrgica, PPGEM, UFF, Volta Redonda, RJ, Brasil. Cirurgiã-Dentista, Doutoranda em Eng ${ }^{a}$. Metalúrgica, PPGEM, UFF, Volta Redonda, RJ, Brasil. Graduanda do curso de Engenharia Mecânica, EEIMVR, UFF, Volta Redonda, RJ, Brasil.
}

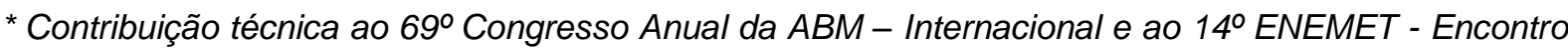
Nacional de Estudantes de Engenharia Metalúrgica, de Materiais e de Minas, 21 a 25 de julho de 2014, São Paulo, SP, Brasil. 


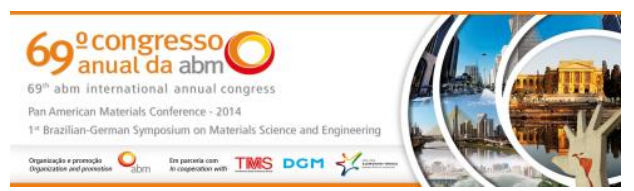

\section{INTRODUÇÃO}

Desde que foram descobertas as transformações sem difusão em metais e ligas, estas têm sido exaustivamente investigadas com interesse teórico e prático, e desta forma a história da superelasticidade e do efeito memória de forma (EMF) inicia-se na década de trinta [1], no entanto só em 1962 o EMF e a superelasticidade foram estudados com maior profundidade em liga 50\%at.Ni-Ti batizada de Nitinol pela Força Naval Americana, sendo esta a primeira liga a ter aplicação prática no acoplamento de tubos do sistema hidráulico de aviões F-14 [2]. Desde então, foram realizadas numerosas pesquisas e a aplicação para estes materiais teve um enorme avanço e diversificando os ramos de aplicação, com as devidas propriedades de recuperação elástica significativa e a menor perda de propriedade ao longo da vida em trabalho. Assim sendo quando se trabalha de modo a produzir ligas superelásticas ou com efeito memória de forma, as características destas irão depender de variáveis como temperatura de processamento, temperatura de encharque, tempo de encharque, nível de deformação, tensão e número de ciclos, que são importantes sob o aspecto de controle do processo de fabricação; os quais juntamente com a composição química do material e controle de impurezas, irão afetar diretamente as características associadas à transformação de fase e microestrutura, incluindo os defeitos e formação de precipitados. Obtendo condições estruturais que a fase de alta temperatura (B2 - austenita, cúbica do tipo $\mathrm{CsCl}$ ) se transforme em martensita em uma única etapa (B19' - monoclínica) ou em duas etapas, com a formação de uma fase martensítica intermediária, denominada fase $R$ (trigonal, com distorção romboédrica no ângulo $\alpha$ ).

Favier e colaboradores, estudaram, com auxílio da técnica de Calorimetria de Diferencial de Varredura (DSC) e ensaios de tração uniaxial, uma liga de NiTi com 50,8 \%at Ni, com três condições distintas: (i) inicialmente submetida a tratamento térmico de recozimento a $500^{\circ} \mathrm{C}$ e resfriada ao ar; (ii) posteriormente a tratamento térmicos de envelhecimento, com temperatura de encharque a $500^{\circ} \mathrm{C}$, com três ciclos consecutivos de 5 minutos cada e resfriamento ao ar; e (iii) envelhecimento constrangido, onde a liga foi submetida à consecutivas deformações de 2,5 / 5,0 e $7,5 \%$ à temperatura ambiente, com subsequente aquecimento a $500^{\circ} \mathrm{C}$ por 5 minutos e resfriamento ao ar. Resultando que tanto na condição inicial, quanto na de

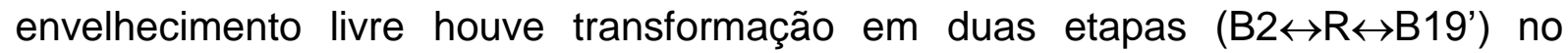
aquecimento e resfriamento, porém as temperaturas de transformação de $B 2 \rightarrow R$ decresceram e as de $\mathrm{R} \rightarrow \mathrm{B} 19^{\prime}$ no envelhecimento livre incrementaram. Enquanto que para 0 envelhecimento constrangido adotado, as temperaturas de transformação de $\mathrm{R} \rightarrow \mathrm{B} 19^{\prime}$ incrementaram mais ainda e passou a ocorrer uma sobreposição nas transformações reversas, apresentando assim quase um único pico de transformação. No entanto estas condições de tratamentos não propiciaram modificações significativas na superelasticidade [3].

Arciniegas e colaboradores estudaram cinco ligas de NiTi, onde o teor em Ni variou entre 49 e $51 \%$ at, com o objetivo de entender o comportamento da propriedade mecânica de dureza associado às fases presentes à temperatura ambiente. As ligas foram submetidas a um tratamento térmico de recozimento para homogeneização a $900^{\circ} \mathrm{C}$ por 24 horas, seguido de solubilização a $800^{\circ} \mathrm{C}$ por 10 minutos com resfriamento em água, e envelhecimento a $500^{\circ} \mathrm{C}$ por 60 minutos. Baseado nos resultados via análise de DSC e Difração de Raios-X (DRX) quanto às transformações de fase e fases presentes à temperatura ambiente, puderam observar que o incremento no valor da dureza está associado à maior presença da

\footnotetext{
* Contribuição técnica ao $69^{\circ}$ Congresso Anual da ABM - Internacional e ao 14ํㅡㄹ ENEMET - Encontro Nacional de Estudantes de Engenharia Metalúrgica, de Materiais e de Minas, 21 a 25 de julho de 2014, São Paulo, SP, Brasil.
} 


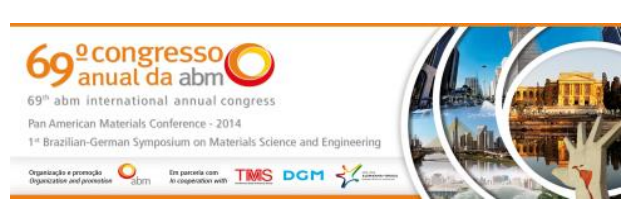

fase B2 em conjunto com a fase R. No entanto, a presença conjunta das fases B2 e B19' promove um decréscimo na dureza, sendo mais evidente esta redução para ligas que possuíam temperaturas $\mathrm{Mi}$ e $\mathrm{Ai}$ (início das transformações martensítica em fase B19' e austenítica, respectivamente), mais próximas da temperatura ambiente, ou seja, uma condição de maior mistura das duas fases B2 e B19' [4].

Desta forma, a motivação deste trabalho está diretamente relacionada ao interesse de se conhecer como as variáveis temperatura e tempo de encharque, vinculadas aos tratamentos térmicos de solubilização e envelhecimento, específicos para ligas forjadas de $\mathrm{NiTi}$ ricas em $\mathrm{Ni}$, irão contribuir para a obtenção de características estruturais e mecânicas que possam a vir obter condições com aspectos superelásticos otimizados.

\section{MATERIAL E MÉTODOS}

\subsection{Material}

O material em estudo refere-se a uma liga de $\mathrm{Ni}$-Ti rica em $\mathrm{Ni}$ (com estimativa via análise semi-quantitativa por EDX/MEV, de aproximadamente 49,2\%at.Ti e $50,8 \%$ atNi), produzida no ITA (Instituto Tecnológico da Aeornaútica), pelo Grupo do Pesquisador Professor Jorge Otubo, através do processo de fusão em forno de indução a vácuo (VIM). Fatias do lingote denominado VIM74, cortadas por meio de corte por eletroerosão (Empresa Elevolt em Volta Redonda / RJ), aproximadamente $90 \mathrm{~g}$ cada, foram refundidas no forno de fusão a arco do ITA.

\subsection{Métodos}

\subsubsection{Processamento}

A liga em estudo, após ser refundida, foi submetida a processamentos termomecânicos de forjamento rotativo, inicialmente com sequência de conformação mecânica a quente, e nas sequências finais com conformação a frio, intercalados por etapas de tratamentos térmicos.

As etapas iniciais de processamento consistiram em conformação termomecânica por intermédio de forjamento rotativo, conforme Figura 1. O primeiro e o segundo passe do processamento termomecânico foram realizados em uma forja rotativa de 4 martelos, sendo que os seis restantes foram realizados em uma forja rotativa de 2 martelos. Antecedendo o primeiro passe até a etapa prévia ao quinto passe, 0 material foi aquecido a $800^{\circ} \mathrm{C}$ (35 minutos para o primeiro passe, e 10 minutos para os passes subsequentes), retirado do forno $e$ introduzido diretamente ao processamento de conformação por forjamento rotativo. Antecedendo os passes do sexto ao oitavo passe, o material foi submetido a um tratamento térmico de solubilização, com homogeneização à $800^{\circ} \mathrm{C}$ por 10 minutos em forno mufla e resfriado em água à temperatura ambiente. Nos dois primeiros passes o material foi submetido a forjamento rotativo numa forja de quatro martelos indicado por F4 na Figura 1, e nas etapas posteriores o material foi submetido a uma forja de dois martelos indicado por F2. O produto final obtido foi uma barra forjada com diâmetro de $3,25 \mathrm{~mm}$, denominado de fim de forjamento (FF).

Posteriormente amostras do final de forjamento (FF) foram submetidas aos tratamentos térmicos de solubilização a $850^{\circ} \mathrm{C}$ por $60,90,120$ minutos e por 850 , $900,950,1000^{\circ} \mathrm{C}$ por 120 minutos, seguido de resfriamento em água à temperatura ambiente, com o intuito de promover e verificar a melhor condição de tratamento que

* Contribuição técnica ao $69^{\circ}$ Congresso Anual da ABM - Internacional e ao 14ํㅡㄹ ENEMET - Encontro Nacional de Estudantes de Engenharia Metalúrgica, de Materiais e de Minas, 21 a 25 de julho de 2014, São Paulo, SP, Brasil. 


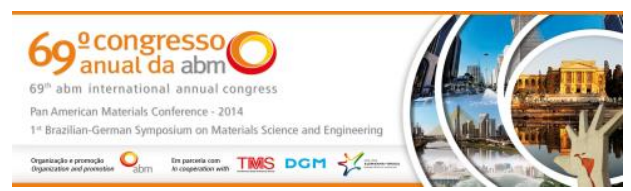

spot size de 550, step size de $1 \mu \mathrm{m}$ com 500x de aumento (amostra final de forjamento) e $0,2 \mu \mathrm{m}$ com $2000 x$ de aumento (amostra solubilizada a $950^{\circ} \mathrm{C}$ por 120 minutos). Tratamento dos dados de EBSD, foi utilizado o critério de limpeza pela eliminação dos pontos com IC $<0,1$ (Índice de Confiança) e adoção da orientação dos vizinhos mais próximos, com sequência única de limpeza para evitar que as regiões associadas a outras fases (segunda fase, óxidos e martensita B19' e/ou fase R) fossem falsamente interpretadas como fase B2 no resultado final. No entanto para as análises associadas aos detectores SE e EDS, as amostras após polimento eletrolítico foram analisadas em condições sem ataque (simplesmente polidas) e com ataque (solução de $50 \mathrm{ml}$ de glicerol, $18 \mathrm{ml}$ de ácido acético, $20 \mathrm{ml}$ de ácido nítrico e $16 \mathrm{ml}$ de ácido fluorídrico, com imersão por 4 minutos para amostra final de forjamento e 6 minutos para amostra solubilizada). Para uso dos detectores de SE e EDS as condições de operação do MEV foram configuradas com tensão de aceleração de $12 \mathrm{KV}$, distância de trabalho de $6 \mathrm{~mm}$ (amostra sem ataque) e 9,5 mm (amostra com ataque), e spot size de 450. Sendo que as amostras observadas com estes detectores, foram analisadas nas condições de amostras embutidas a frio.

\section{RESULTADOS E DISCUSSÃO}

Com o uso do detector de elétrons secundários do MEV pode-se constatar que o material na condição final de forjamento, conforme Figura 2a, é constituído de uma matriz metálica de NiTi (região escura) associada à fase B2, além da presença de uma segunda fase (pontos claros) possivelmente precipitado de $\mathrm{TiC}$ e/ou precipitado de $\mathrm{Ni}$ e $\mathrm{Ti}$, que através do seu posicionamento na matriz revela a direção de forjamento. Já a Figura $2 b$ exibe a microestrutura da matriz metálica de NiTi após ataque, com os vazios provenientes da remoção da segunda fase. Por intermédio do resultado da análise composicional via EDX em pontos associados a esta segunda fase, verificou-se em alguns pontos claros da microestrutura a presença de $\mathrm{Ti}, \mathrm{Ni}$ e $\mathrm{C}$, os quais possivelmente estão associados ao precipitado de TiC, sendo a Figura 2c o exemplo de uma análise composicional destes carbetos. Em outros pontos claros da microestrutura, com auxílio do detector de EDX, há a presença somente de $\mathrm{Ni}$ e $\mathrm{Ti}$ com percentuais distintos e mais elevados em $\mathrm{Ni}$ que a matriz $\mathrm{NiTi}$, Figura 2d, os quais possivelmente estão associados a precipitados binários de $\mathrm{Ni}$ e $\mathrm{Ti}\left(\mathrm{Ni}_{4} \mathrm{Ti}_{3}\right)$. Característica esta, quanto à presença de segunda fase somente vinculada a $\mathrm{Ni}$ e $\mathrm{Ti}$, o que evidencia a possibilidade de se melhorar o tratamento térmico de solubilização, entre as etapas de forjamento rotativo a frio, com o intuito de produção de amostras com o final de forjamento sem a presença dos precipitados de Ni e Ti. Precipitados estes que podem ter sido formados nas etapas iniciais de reaquecimento das amostras, entre os passes de forjamento rotativo a quente, e incorporados à matriz por uma ineficaz dissolução nos tratamentos finais de solubilização, entre os passes de forjamento rotativo a frio. A Figura $2 e$, exibe a análise composicional típica da matriz NiTi rica em $\mathrm{Ni}$, a saber $50,8 \%$ atNi.

Com base nos resultados da análise de EBSD com indexação dos padrões de Kikuchi para identificação da fase B2, pode-se confirmar a presença da fase B2 formando a matriz metálica da amostra final de forjamento, Figura 3a, constituída de grãos poligonais com distintas orientações e com pequenas variações no interior de um mesmo grão. Todavia se verifica pelos baixos valores do índice de confiança (IC), apresentados no mapa referente à Figura 3b, que a matriz possui provavelmente um alto nível de tensões internas associadas à presença dos precipitados, evidenciados na análise microestrutural na Figura 2 e confirmados na

* Contribuição técnica ao $69^{\circ}$ Congresso Anual da ABM - Internacional e ao 14ํㅡㄹ ENEMET - Encontro Nacional de Estudantes de Engenharia Metalúrgica, de Materiais e de Minas, 21 a 25 de julho de 2014, São Paulo, SP, Brasil. 


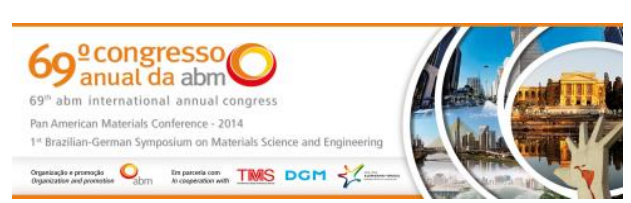

análise de EDX, e/ou possivelmente algum encruamento residual na fase B2 devido à última etapa de forjamento rotativo a frio ter sido realizada a uma temperatura muito superior a $A_{f}$ da amostra final de forjamento. Este caráter, vinculado a tensões internas, é revelado pelo fato do mapa de IC ter poucas regiões de tons branco ou cinza claro (associado ao IC de valor alto, próximo a 1), e muitas regiões de tons preto ou cinza escuro (associados a IC de valor baixo, tendendo a 0). Aspecto este em concordância com a literatura para ligas com composições e condições de processamento similares [5-8].

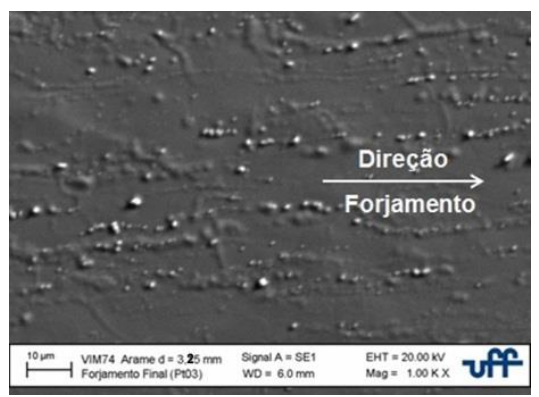

(a)

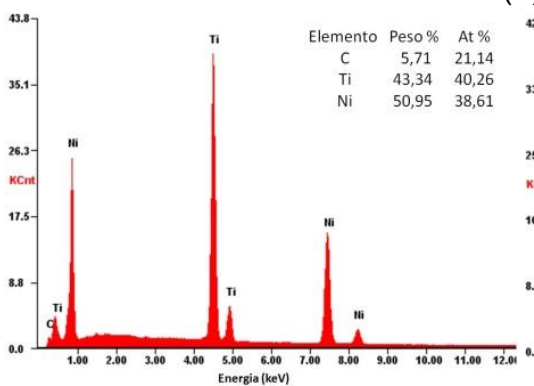

(c)

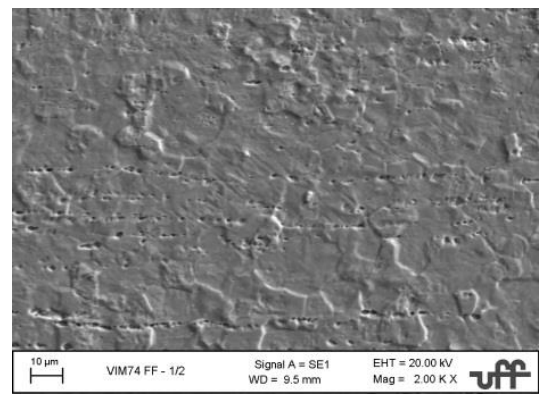

(b)

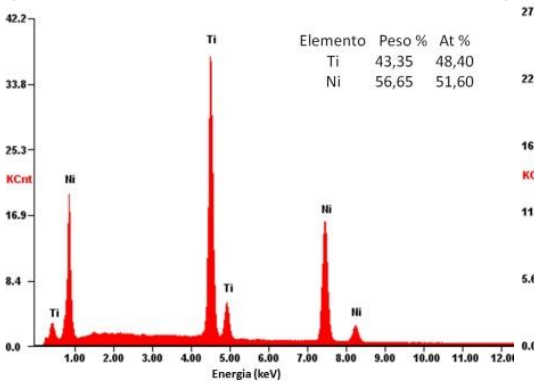

(d)

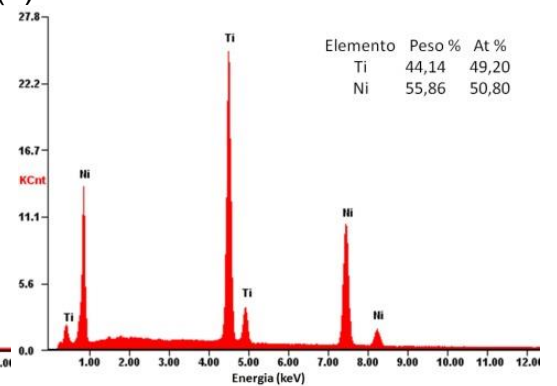

(e)

Figura 2. Aspecto microestrutural, análise MEV com detector de SE, da amostra final de forjamento: (a) pontos claros na matriz NiTi (região escura) - sem ataque 1000x, (b) cavidades da segunda fase removida "após ataque" para revelar a microestrutura da matriz de B2 - 2000x. Análise composicional na condição sem ataque (Figura 2a) via EDX da: (c) segunda fase de maior dimensão constituída de $\mathrm{Ni}$, Ti, C, e rica em carbono possivelmente TiC; (d) segunda fase de menor dimensão constituída de $\mathrm{Ni}$ e Ti, rica em Ni possivelmente $\mathrm{Ni}_{4} \mathrm{Ti}_{3} ;$ (e) matriz NiTi rica em Ni.
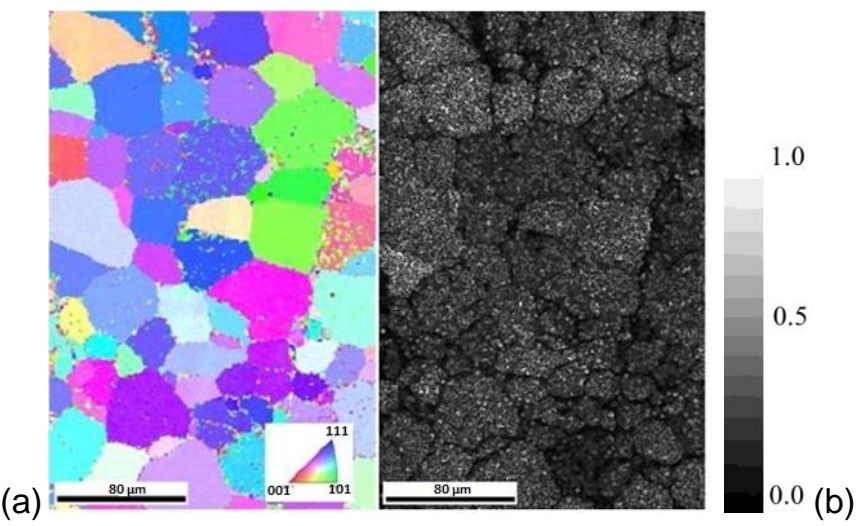

Figura 3. Resultados de EBSD da amostra final de forjamento (FF):

(a) Mapa de orientação cristalográfica, (b) mapa de IC e sua respectiva escala.

O espectro de DRX apresentado na Figura 4a refere-se à amostra de fim de forjamento $(F F)$, onde se verifica somente a presença de dois planos. O primeiro plano é (110) com intensidade máxima de pico de $1678 \mathrm{cps}$ com $2 \theta$ de 49,80ㅜ응

* Contribuição técnica ao 69 Congresso Anual da ABM - Internacional e ao 14ํㅡㄹ ENET - Encontro Nacional de Estudantes de Engenharia Metalúrgica, de Materiais e de Minas, 21 a 25 de julho de 2014, São Paulo, SP, Brasil. 


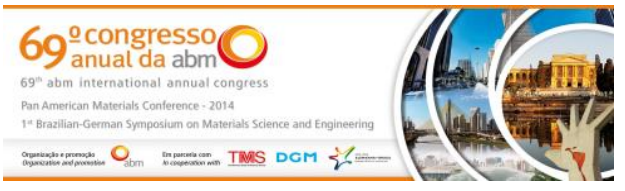

segundo plano é (211) com intensidade máxima de pico de $226 \mathrm{cps} \operatorname{com} 2 \theta$ de $93,30^{\circ}$. Estes planos são referentes à matriz $\mathrm{NiTi}$ de estrutura cúbica tipo $\mathrm{CsCl}$ referente à fase $\mathrm{B} 2$, sendo portanto austenítica a referida amostra à temperatura ambiente.

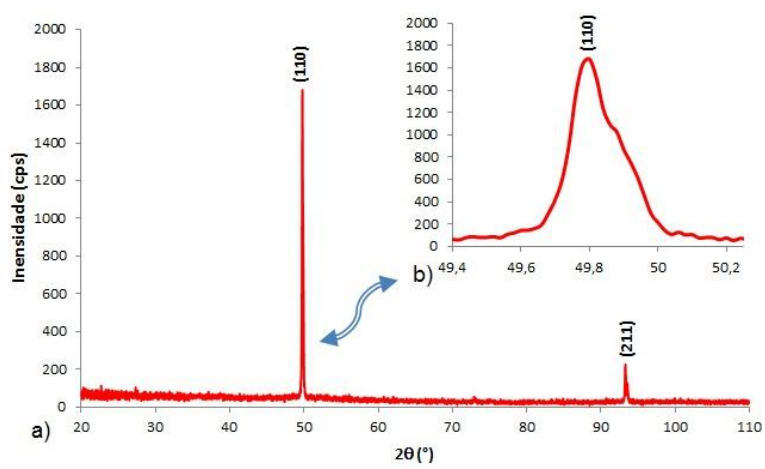

Figura 4. Espectro de DRX da amostra final de forjamento (FF), com indicação dos picos dos planos (a) (110) e (211) de difração de B2, e (b) detalhamento do pico do plano (110).

O que vem a corroborar com os resultados da análise de EDX e EBSD (Figuras 2 e 3, respectivamente), associados ao fator composicional para justificativa da estabilidade da fase B2 à temperatura ambiente, devido ao fato do material ser uma liga rica em $\mathrm{Ni}$, com teor de $\mathrm{Ni}$ suficientemente alto para reduzir a temperatura de transformação martensítica para valores inferiores à temperatura ambiente [9].

Focando-se no pico de difração referente ao plano (110) de B2 (Figura 4b), verificase uma assimetria na forma do pico que pode estar vinculada ao fator de tensão residual, devido à última etapa de processamento ter sido o forjamento a frio à temperatura ambiente, o qual provavelmente promoveu um grau de encruamento da austenita presente no material a ser deformado nesta etapa [3]. Podendo desta forma, apresentar indícios de uma possível sobreposição do pico (110) de B2 com picos de difração da fase $R\left((20-2) \operatorname{com} 2 \theta=49,1260^{\circ}\right.$, e $\left.(220) \operatorname{com} 2 \theta=49,7707^{\circ}\right)$. Com o intuito de promover a completa dissolução dos precipitados de $\mathrm{Ni}$ e $\mathrm{Ti}$ e remover tensões, a amostra do final de forjamento (FF) foi solubilizada em temperaturas de encharque e tempos distintos de permanência. Um grupo de amostras foi tratado a $850^{\circ} \mathrm{C}$ em tempos de encharque de 60,90 e 120 minutos, e para outro grupo de amostras manteve-se constante o tempo de encharque em 120 minutos e variou-se a temperatura de encharque em 900, 950 e $1000^{\circ} \mathrm{C}$. Os resultados da análise de dureza, realizados no centro e 1/4 do diâmetro, das amostras submetidas aos tratamentos térmicos de solubilização são comparados com a amostra final de forjamento e apresentados na Figura 5. Os dados são apresentados em função do incremento da temperatura e tempo de encharque no tratamento de solubilização. Podendo-se verificar um aumento significativo na dureza do material com o aumento do tempo de encharque para as amostras tratadas a $850^{\circ} \mathrm{C}$, e um aumento na dureza com o aumento da temperatura de encharque para as amostras tratadas com tempo de encharque de 120 minutos.

Verifica-se uma evolução definida de incremento das durezas medidas nas regiões de centro e 1/4 do diâmetro das amostras em função da temperatura de encharque e/ou tempo de encharque, podendo-se afirmar que, de modo geral, os resultados de dureza evidenciam um provável incremento na fração volumétrica de austenita presente à temperatura ambiente nas condições analisadas. Tendo-se como foco escolher a rota de tratamento térmico que trará a maior fração volumétrica de B2 à temperatura ambiente (fase B2 é individualmente mais dura que a fase B19' e a fase R), natural seria escolher a condição de tratamento de solubilização a $1000^{\circ} \mathrm{C}$

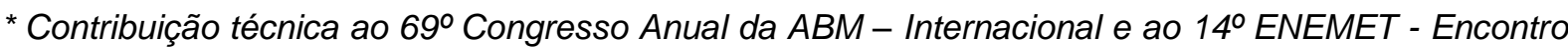
Nacional de Estudantes de Engenharia Metalúrgica, de Materiais e de Minas, 21 a 25 de julho de 2014, São Paulo, SP, Brasil.
} 


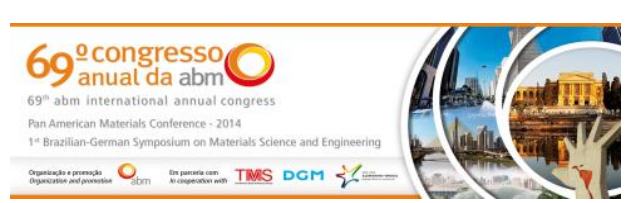

A Figura $6 \mathrm{~b}$ diz respeito aos resultados da análise de DRX com o mesmo tempo de encharque de 120 minutos e temperaturas distintas de 850, 900, 950 e $1000^{\circ} \mathrm{C}$, onde se verifica um decréscimo na intensidade difratada em comparação à condição final de forjamento, provavelmente devido ao crescimento de grão, e ainda, este decréscimo na intensidade difratada é tanto maior, quanto maior for a temperatura de encharque, exceto pelo leve incremento entre as amostras com tratamento a $900^{\circ} \mathrm{C}$ e $950^{\circ} \mathrm{C}$. Além disso, se verifica que a posição relativa dos picos se desloca para a direita com o incremento da temperatura, ou seja, há um incremento na posição $2 \theta$ em relação aos picos com o incremento da temperatura.
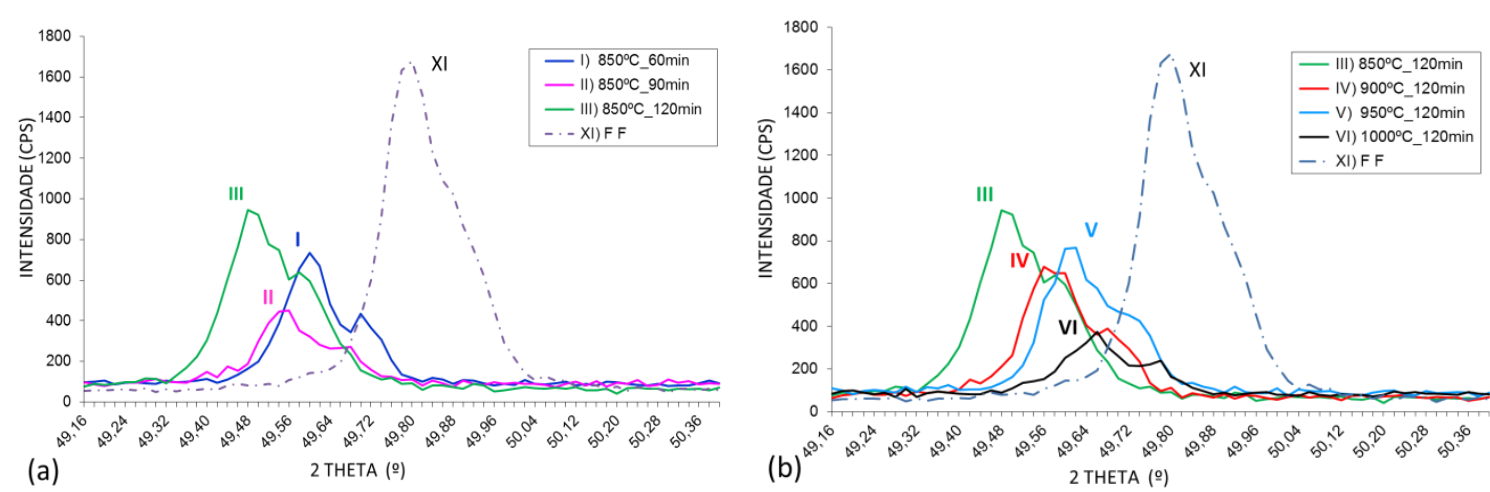

Figura 6. Seleção do espectro de DRX das amostras com tratamentos térmicos de solubilização relativo ao pico correspondente ao plano (110) de B2 e indícios dos picos (20-2) e (220) da fase-R (à esquerda e à direita do pico (110)), sendo (a) os tratamentos a 850ํำ por 60,90 e 120 minutos, e (b) os tratamentos por 120 minutos a $850,900,950$ e $1000^{\circ} \mathrm{C}$.

Tal comportamento deve estar associado aos precipitados oriundos da condição final de forjamento, que com o incremento da temperatura de solubilização promove uma menor dimensão e fração volumétrica, provavelmente impactando na redução das temperaturas de transformação e estabilizando a fase B2 à temperatura ambiente, provavelmente em conjunto com alguma fase $R$, como já discutido anteriormente na Figura 6a. Após analisar os gráficos dos espectros de difração de Raio-X, Figuras 6(a,b), e mantendo-se foco em obter a maior fração volumétrica da fase B2 à temperatura ambiente (fase mais dura), pela maior intensidade de pico (944 cps) do plano (110) de B2 a escolha imediata seria a condição de tratamento térmico a $850^{\circ} \mathrm{C}$ por 120 minutos, porém o seu correspondente valor da dureza de 226 HV é baixo, Figura 5, comparado a 249 HV para a condição de tratamento térmico a $950^{\circ} \mathrm{C}$ por 120 minutos com intensidade de pico (768 cps), segundo lugar em intensidade de pico mas demonstrando um perfil de pico menos assimétrico que a $850^{\circ} \mathrm{C}$ por 120 minutos, evidenciando maior homogeneidade. Sendo assim selecionada a condição prévia de solubilização a $950^{\circ} \mathrm{C}$ por 120 minutos para os tratamentos térmicos de envelhecimento. Com base nesta seleção foi conduzida análise microestrutural, composicional e de textura na amostra, com auxílio do MEV e dos detectores de elétrons secundários, EDX e EBSD. Ao observar a microestrutura da amostra solubilizada a $950^{\circ} \mathrm{C}$ por 120 minutos sem ataque e após ataque para revelar a matriz de B2, Figuras $7(a, b)$, verifica-se um aparente crescimento de grão da condição após ataque, Figura $7 \mathrm{~b}$, quando comparada à condição final de forjamento, Figura $2 b$. No entanto a segunda fase presente e evidenciada com auxílio do detector de elétrons secundários, Figuras 7(a,b), mantém o mesmo aspecto morfológico (pontos claros arredondados), e

\footnotetext{
* Contribuição técnica ao $69^{\circ}$ Congresso Anual da ABM - Internacional e ao 14ํㅡㄹ ENEMET - Encontro Nacional de Estudantes de Engenharia Metalúrgica, de Materiais e de Minas, 21 a 25 de julho de 2014, São Paulo, SP, Brasil.
} 


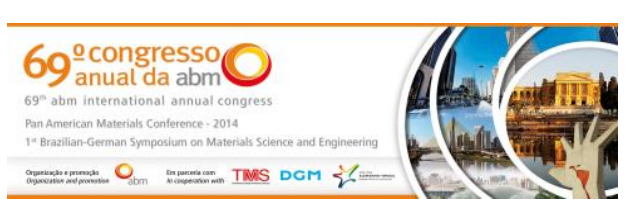

característica composicional associada a Ti e C evidenciada pela análise de EDX, Figura 7c.

Do mesmo modo que para a amostra na condição final de forjamento, com base nos resultados da análise de EBSD com indexação dos padrões de Kikuchi para identificação da fase B2, pode-se confirmar a presença da fase B2 formando a matriz metálica da amostra com tratamento de solubilização a $950^{\circ} \mathrm{C}$ por 120 minutos, Figura 8a, constituída de grãos poligonais com distintas orientações e com pequenas variações no interior de um mesmo grão. No entanto verifica-se que os valores do índice de confiança aumentaram para a condição solubilizada a $950^{\circ} \mathrm{C}$ por 120 minutos, apresentados no mapa referente à Figura 8b, quando comparada à condição final de forjamento, Figura $3 \mathrm{~b}$; o que provavelmente está associado à redução das tensões residuais promovidas pelo tratamento de solubilização. Os pontos com baixos valores de IC (tons preto, tendendo a zero) estão associados aos contornos de grão e possivelmente às regiões associadas à segunda fase evidenciada pelas análises com uso dos detectores de elétrons secundários (SE) e EDX, Figura 7. Aspecto este em concordância com a literatura para ligas com composições similares submetidas a processamento prévio de trabalho mecânico a frio e posterior tratamento térmico para recuperação/recristalização [5,7].

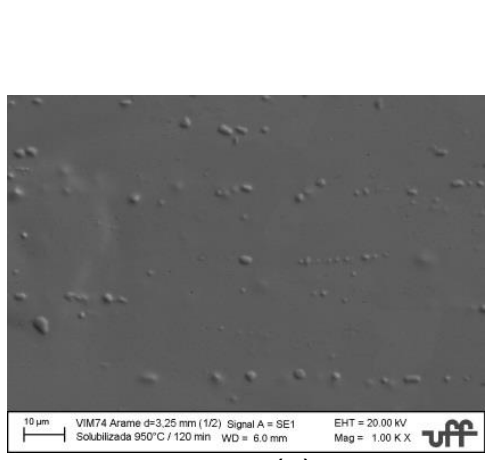

(a)

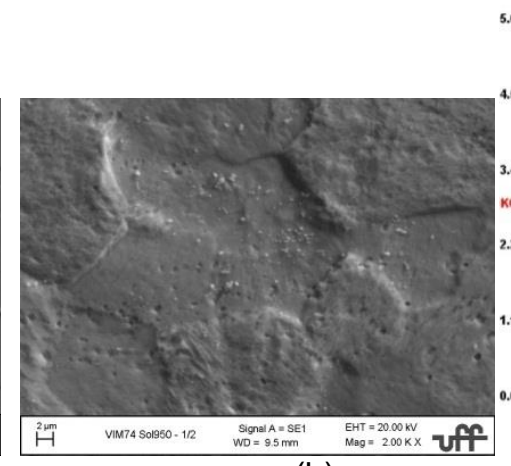

(b)

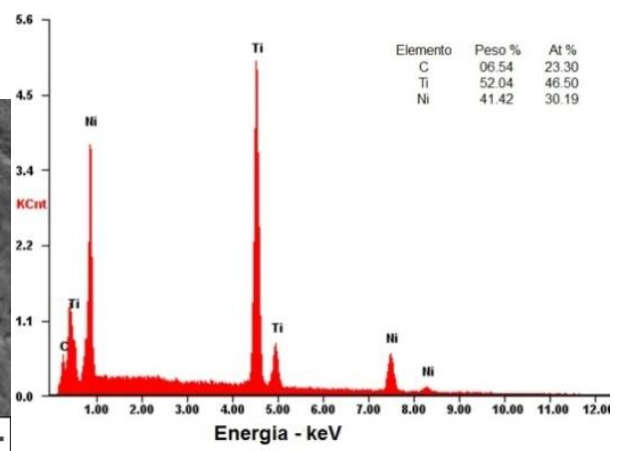

(c)

Figura 7. Aspecto microestrutural da amostra com tratamento térmico de solubilização a $950^{\circ} \mathrm{C}$ por 120 minutos (a) sem ataque (1000x), e (b) após ataque (2000x), associados à (c) análise por EDX nos pontos claros arredondados (segunda fase) na matriz austenítica.

(a)

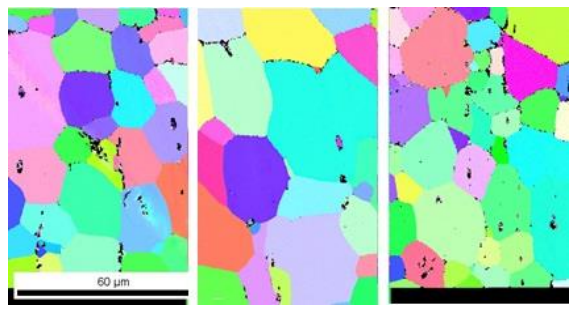

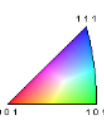

(b)
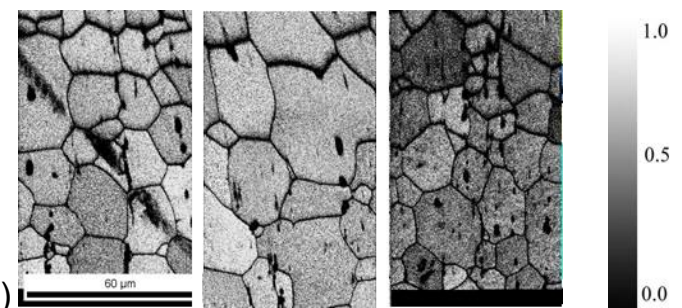

Figura 8. Resultado da análise de EBSD da amostra na condição solubilizada à $950^{\circ} \mathrm{C}$ por 120 minutos, em três distintas regiões: (a) Mapa de orientação cristalográfica e seu respectivo triângulo unitário de orientações; (b) Mapa de Índice de Confiança e sua respectiva escala.

Após a seleção da condição de tratamento de solubilização a $950^{\circ} \mathrm{C}$ por 120 minutos, as amostras foram submetidas a tratamentos térmicos para envelhecimento a $350,400,450,500,550$ e $600^{\circ} \mathrm{C}$ por 30 e 60 minutos, seguido de resfriamento em água à temperatura ambiente, e logo após foram realizados ensaios de dureza tanto no centro quanto a $1 / 4$ do diâmetro, e de acordo com a Figura 9(a,b), verifica-se tendência de decréscimo dos valores da dureza com aumento da temperatura de

* Contribuição técnica ao $69^{\circ}$ Congresso Anual da ABM - Internacional e ao 14ํㅡㄹ ENEMET - Encontro Nacional de Estudantes de Engenharia Metalúrgica, de Materiais e de Minas, 21 a 25 de julho de 2014, São Paulo, SP, Brasil. 
encharque no tratamento de envelhecimento em todas as condições analisadas. Este decréscimo de dureza provavelmente deve estar associado ao efeito da presença de precipitado $\mathrm{Ni}_{4} \mathrm{Ti}_{3}$ durante o tratamento de envelhecimento [11], o qual possivelmente promoveu com sua presença a formação de tensões residuais na matriz metálica fator este que em ligas de $\mathrm{NiTi}$ com superelasticidade, se reflete na transformação de fase com decréscimo da formação da fase $\mathrm{R}$ em conjunto com a matriz de B2 resultando numa redução da dureza com aumento da temperatura de envelhecimento [4].

A Figura 10 sumariza os resultados das difrações de Raio-X das amostras envelhecidas, onde se verifica que a condição de exposição a $350^{\circ} \mathrm{C}$ por 30 minutos apresentou a máxima intensidade de pico (1162 cps) do plano (110) de B2, além de exibir o perfil de intensidade de pico mais simétrico (mais homogêneo) dentre todas condições analisadas, associado com a maior dureza (Figura 9a), sendo portanto, selecionada entre as candidatas - pelas evidências da presença de B2 em conjunto com a fase $R[3,4]$.

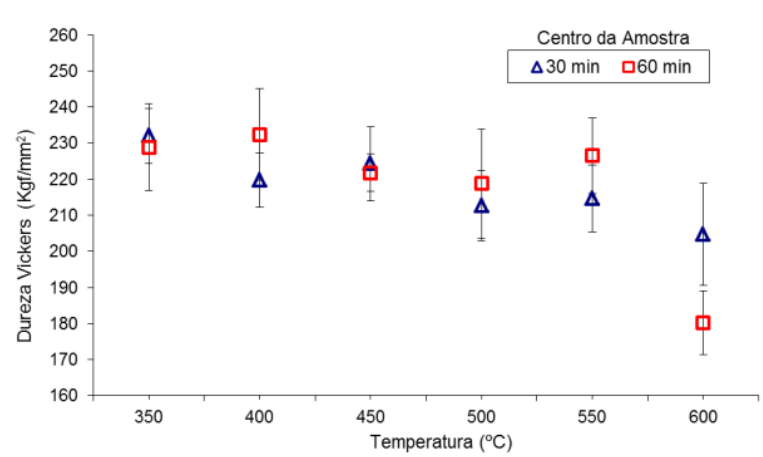

(a)

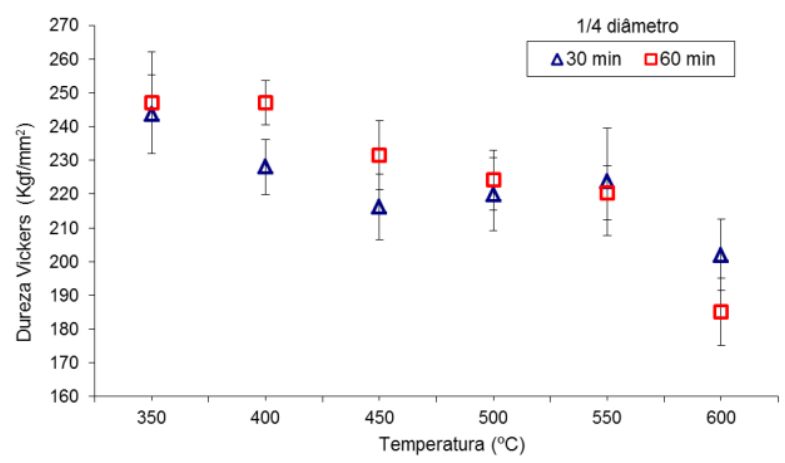

(b)

Figura 9. Evolução da Dureza em função da Temperatura de Envelhecimento e Tempo de Tratamento de 30 e 60 minutos (a) no centro e (b) 1/4 do diâmetro das amostras de liga NiTi rica em Ni em estudo.

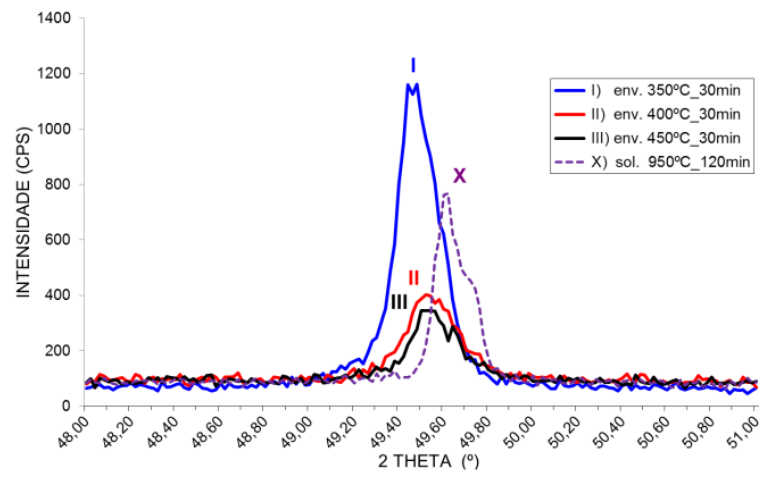

(a)

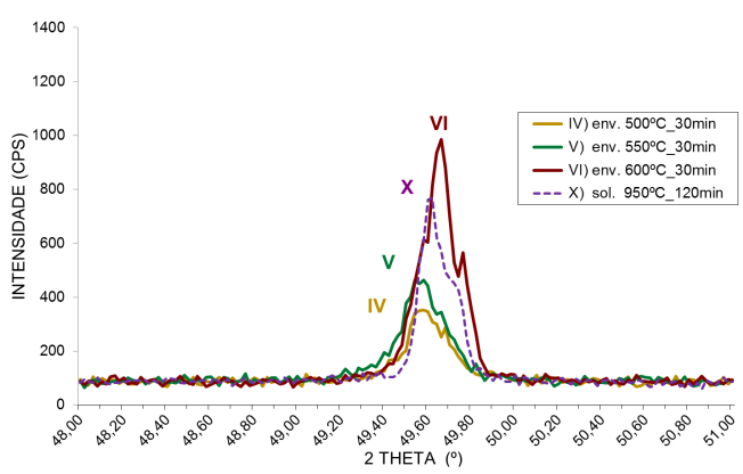

(b)

\footnotetext{
* Contribuição técnica ao 69ำ Congresso Anual da ABM - Internacional e ao 14ํㅡㄹ ENEMET - Encontro Nacional de Estudantes de Engenharia Metalúrgica, de Materiais e de Minas, 21 a 25 de julho de 2014, São Paulo, SP, Brasil.
} 


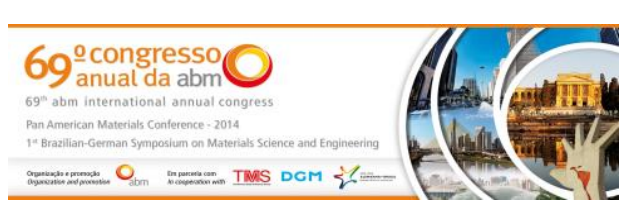

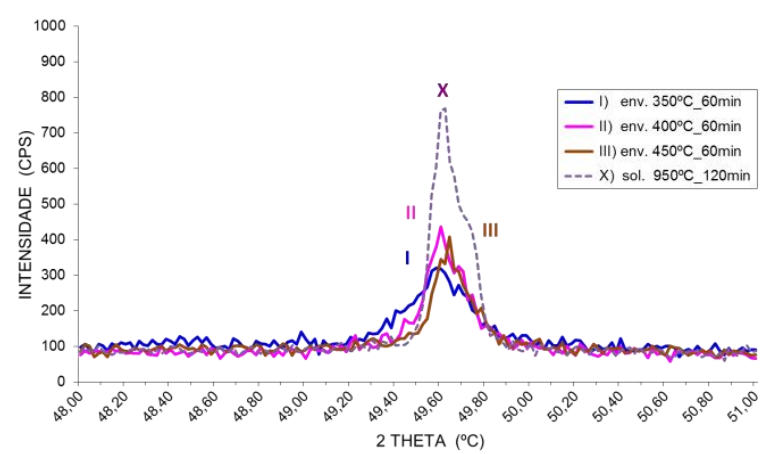

(c)

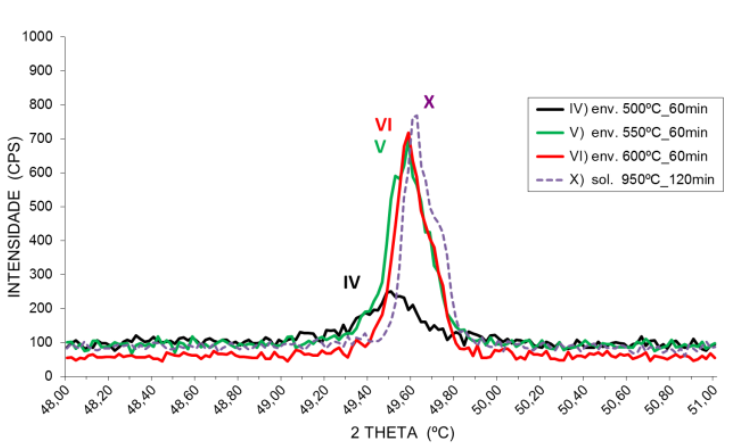

(d)

Figura 10. Espectros de DRX com detalhamento do pico do plano (110) de B2 para amostras com tratamento de envelhecimento em distintas temperaturas e tempos de encharque, com prévia solubilização a $950^{\circ} \mathrm{C}$ por 120 minutos.

\section{CONCLUSÃO}

Com base nos resultados apresentados e suporte da literatura quanto a características e propriedades promissoras a aplicações superelásticas, pode-se concluir que:

- as condições adotadas de tratamentos térmicos entre as etapas de forjamento até atingir a condição final de forjamento, podem ser otimizadas no sentido de se melhorar a homogeneização da matriz;

- a rota proposta mais promissora para a solubilização foi a condição de tratamento a $950^{\circ} \mathrm{C}$ por 120 minutos com resfriamento em água à temperatura ambiente, devido às evidências de uma maior fração da fase B2 à temperatura ambiente associada a uma pequena variação de dureza ao longo do seu diâmetro;

- a rota proposta mais promissora para o envelhecimento foi a condição de tratamento a $350^{\circ} \mathrm{C}$ por 30 minutos com resfriamento em água à temperatura ambiente, pois não verificou-se uma aparente redução significativa na fração de B2, em conjunto com a fase $\mathrm{R}$, e dureza do material à temperatura ambiente.

\section{Agradecimentos}

Os autores agradecem ao Professor J. Otubo e aos pós-graduandos J.P.Toseti e G.H.T.A. da Silva, pela doação dos materiais de partida, e pelo apoio no uso da infraestrutura do Instituto Tecnológico da Aeronáutica para realização deste trabalho. Ao Laboratório Multiusuário de Microscopia Eletrônica (LMME) da UFF pela utilização do MEV e equipamentos de preparação e análise de amostras. A.S.P. e A.C.S.R. agradecem à Faperj pela bolsa de IC (2012). A.S.P e S.B.R. agradecem a CAPES pela bolsa de doutoramento (2013).

\section{REFERÊNCIAS}

1 Pereira AM. Deformação plástica severa por ECAP de ligas com memória de forma. Tese de Mestrado. Lisboa: Universidade Nova de Lisboa; 2013.

2 Otsuka K, Wayman CM. Shape Memory Materials. Cambridge University Press. 1998; $1^{\text {st }}$ ed:267-281.

3 Favier D, Liub Y, Orgeas L, Sandel A, Debovea L, Comte-Gazc P, Influence of thermomechanical processing on the superelastic properties of a Ni-rich $\mathrm{NiTi}$ shape memory alloy. Materials Science and Engineering A. 2006; 429:130-136.

\footnotetext{
* Contribuição técnica ao $69^{\circ}$ Congresso Anual da ABM - Internacional e ao 14ํㅡㄹ ENEMET - Encontro Nacional de Estudantes de Engenharia Metalúrgica, de Materiais e de Minas, 21 a 25 de julho de 2014, São Paulo, SP, Brasil.
} 


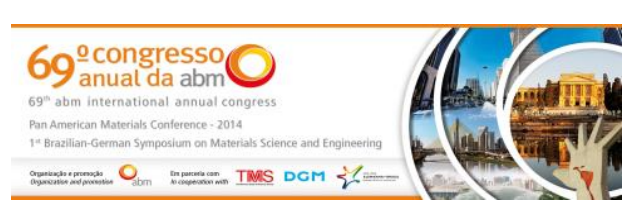

4 Arciniegas M, Casals J, Manero JM, Peña J, Gil FJ. Study of hardness and wear behaviour of NiTi shape memory alloys. Journal of Alloys and Compounds. 2008; 460:213-219.

5 Vojtĕcha $D$, Vodĕrováa $M$, Kubáseka $J$, Nováka $P$, Šedáa $P$, Michalcováa $A$, et al. Effects of short-time heat treatment and subsequent chemical surface treatment on the mechanical properties, low-cycle fatigue behavior and corrosion resistance of a $\mathrm{Ni}-\mathrm{Ti}$ $(50.9$ at.\% $\mathrm{Ni}$ ) biomedical alloy wire used for the manufacture of stents. Materials Science and Engineering. 2011; A528:1864-1876.

6 Suresh KS, Bhaumik SK, Suwas S. Effect of thermal and thermo-mechanical cycling on the microstructure of Ni-rich NiTi shape memory alloys. Materials Letters. 2013; 99:150153.

7 Wang X, Li C, Verlinden B, Humbeeck, Van J. Effect of grain size on aging microstructure as reflected in the transformation behavior of a low-temperature aged Ti50.8 at.\% Ni alloy. Scripta Materialia. 2013; 69:545-548.

8 Mao SC, Luo JF, Zhang Z, Wu MH, Liu Y, Han XD. EBSD studies of the stress-induced B2-B19' martensitic transformation in NiTi tubes under uniaxial tension and compression. Acta Materialia. 2010; 58:3357-3366.

9 Libenson C, Gil FJ, Planell JA. Differences in the pseudoelasticity behaviour of NiTi orthodontic wires. Journal of Materials Science: Materials in Medicine. 1993; 4:281-284.

10 Chiang LJ, Li CH, Hsu YF, Wang WH. Age-induced four-stage transformation in Ni-rich NiTi shape memory alloys. Journal of Alloys and Compounds. 2008; 458:231-237.

11 Nishida M, Wayman CM, Honma. Precipitation Process in Near-equiatomic TiNi Shape Memory Alloys. ASM International, Metallurgical Transactions A. 1986; 17:1505-1515.

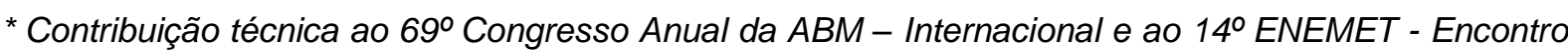
Nacional de Estudantes de Engenharia Metalúrgica, de Materiais e de Minas, 21 a 25 de julho de 2014, São Paulo, SP, Brasil.
} 